\title{
Dysmenorrhea is associated with a higher incidence of pain after diagnostic hysteroscopy or treatment: $A$ commentary
}

\author{
Giustino Varrassi ${ }^{1, *}$
}

${ }^{1}$ Paolo Procacci Foundation, Via Tacito 7, 00193 Roma, Italy

\author{
*Correspondence \\ giuvarr@gmail.com (Giustino Varrassi)
}

The recent article published in Signa Vitae, addressing the important topic of postoperative pain perception in patients affected by dysmenorrhea, is very interesting [1]. The results were very clear: "The incidence of pain after the procedure (diagnostic or therapeutic hysteroscopy) in patients with dysmenorrhea was higher than that of patients without dysmenorrhea $(77.8 \%$ vs. $45.2 \%, P=0.011)$ " [1]. These results are very important and encouraging the researcher to better explore the still controversial field of pain pathophysiology in dysmenorrhea patients. In fact, dysmenorrhea, both primary and secondary, is a quite discussed gynecological pathology, [2] sometimes put together to all the other pelvic pain syndromes, especially in adolescents [3].

Dysmenorrhea is the leading cause of recurrent short-term school absence, during adolescence, and it is a very common problem in adult women [4]. Interesting reviews are making a clear point on its epidemiology [5]. Diagnosis is quite standardized, and endometriosis is the most common cause [6]. Its symptoms are quite clear, especially the somatic symptoms [7]. Frequently, it is associated to allodynia, which is an increasing disturbing factor [8].

Its diagnosis and treatment were objects of a recent consensus guidelines, which has made clear many aspects [9]. Still, the heat therapy in primary dysmenorrhea seems to have an important role, especially to ameliorate the quality of life [10].

Very recently, the topic of dysmenorrhea associated to chronic pain has been deeply reviewed, concluding that dysmenorrhea is a general risk factor for the possibility to develop a chronic pain condition in adult women [11]. Hence, the study published on Signa Vitae on its influence on acute postoperative pain is particularly timing [1]. It would also be interesting to study this phenomenon related to other data appeared in the literature, showing the influence of different phases of the menstrual cycle on pain perception, after gynecological surgery [12]. We hope that this commentary may open the discussion on the topic.

\section{ACKNOWLEDGMENT}

The author is grateful to the Paolo Procacci Foundation for the support in the editing of the manuscript.

\section{CONFLICT OF INTEREST}

The author is the editor in chief of this journal. He does not have any other potential conflict of interest with this publication.

\section{REFERENCES}

[1] Pan YY, Jin SH, Luo S, Li RR, Tu YY, Jin D, et al. Dysmenorrhea is associated with a higher incidence of pain after diagnostic hysteroscopy or treatment. Signa Vitae. 2021. DOI: 10.22514/sv.2020.16.0117

[2] Iacovides S, Avidon I, Baker FC. What we know about primary dysmenorrhea today: a critical review. Human Reproduction Update. 2015; $21: 762-778$

[3] As-Sanie S, Smorgick N. Pelvic pain in adolescents. Seminars in Reproductive Medicine. 2018; 36: 116-122.

[4] French L. Dysmenorrhea. American Family Physician. 2005; 71: $285-$ 291.

[5] De Sanctis V, Soliman A, Bernasconi S, Bianchin L, Bona G, Bozzola M, et al. Primary dysmenorrhea in adolescents: prevalence, impact and recent knowledge. Pediatric Endocrinology Reviews. 2015; 13: 512-520.

[6] Osayande AS, Mehulic S. Diagnosis and initial management of dysmenorrhea. American Family Physician. 2014; 89: 341-346.

[7] Zuckerman RM, Silton RL, Tu FF, Eng JS, Hellman KM. Somatic symptoms in women with dysmenorrhea and noncyclic pelvic pain. Archives of Women's Mental Health. 2018; 21: 533-541.

[8] Jarrell J, Arendt-Nielsen L. Allodynia and dysmenorrhea. Journal of Obstetrics and Gynaecology Canada. 2016; 38: 270-274.

[9] Burnett M, Lemyre M. No. 345-primary dysmenorrhea consensus guideline. Journal of Obstetrics and Gynaecology Canada. 2017; 39: 585595.

[10] Jo J, Lee SH. Heat therapy for primary dysmenorrhea: a systematic review and meta-analysis of its effects on pain relief and quality of life. Scientific Reports. 2018; 8: 16252.

[11] Li R, Li B, Kreher DA, Benjamin AR, Gubbels A, Smith SM. Association between dysmenorrhea and chronic pain: a systematic review and metaanalysis of population-based studies. American Journal of Obstetrics and Gynecology. 2020; 223: 350-371.

[12] Piroli A, Mattei A, Carta G, D’Alfonso A, Palermo P, Marinangeli F, et al. Influence of menstrual cycle phase on pain perception and analgesic 
requirements in young women undergoing gynecological laparoscopy. Pain Practice. 2019; 19: 140-148.
How to cite this article: Giustino Varrassi. Dysmenorrhea is associated with a higher incidence of pain after diagnostic hysteroscopy or treatment: A commentary. Signa Vitae. 2021;17(2):214-215. doi:10.22514/sv.2021.022. 